\title{
SERVITE
}

\section{Hambatan Komunikasi Event Project Team dengan Account Executive pada Perusahaan Jasa Event Organizer Twisbless}

\author{
Innaka Dwi Hasanti \\ STIKOM The London School of Public Relations, Jakarta - Indonesia
}

\begin{abstract}
ABSTRAK
Berhasilnya sebuah event membutuhkan komunikasi yang baik antara tim project dan account executive pada perusahaan jasa event organizer. Project Team bertugas mengeksekusi acara di lapangan sedangkan tugas account executive adalah menjaga komunikasi antara tim internal perusahaan dengan kliennya. Tujuan penelitian ini untuk mengetahui arus komunikasi organisasi yang diterapkan tim project dan account executive di Event Organizer Twisbless, serta untuk mengetahui hambatan komunikasi organisasi di perusahaan jasa Twisbless. Teori yang digunakan adalah teori komunikasi organisasi. Metode penelitian yang digunakan adalah kualitatif. Subjek penelitiannya adalah karyawan Twisbless yang berperan sebagai tim project dan account executive. Data diperoleh melalui wawancara dan observasi terhadap empat informan. Komunikasi organisasi yang diterapkan tim project dan account executive di Twisbless meliputi komunikasi internal dan eksternal. Komunikasi internal terbagi empat arus: komunikasi arus atas, komunikasi arus bawah, komunikasi diagonal, dan komunikasi horizontal. Terdapat hambatan pada proses komunikasi organisasi yaitu gangguan teknis, semantik, rintangan fisik, psikologi dan rintangan kerangka berpikir sehingga menimbulkan kendala dan dampak yang berpengaruh terhadap kelancaran suatu event.
\end{abstract}

Kata kunci: account executive; event; komunikasi organisasi; project team

\section{Communication Barriers between Event Project Team and Account Executive at Twisbless Event Organizer}

\begin{abstract}
The success of an event requires good communication between the project team and account executive involved in the event. Project team in an event organizer tasked to execute events in the field while the task of account executive is to maintain communication between the company's internal team with clients and accommodate all the things needed and desired by clients. The purpose of this research is to determine the flow of organizational communication applied by the project team and account executive at Event Organizer Twisbless as well as knowing the obstacles of organization communication in Twisbless. The theory used in this research is the theory of organizational communication. The research method used is qualitative method. Subjects in this research were employees of Twisbless who act as project team and account executive. Data collection techniques used in this research are interviews and observations of four people who work at Twisbless. This research results in the organizational communication applied by the project team and account executive at Twisbless is an internal and external communication where internal communication is divided into four currents namely, upward communication, downward communication, diagonal communication, and horizontal communication. Then there are various kinds of barriers that exist in the process of organizational communication that is technical disturbances, semantic disorders,
\end{abstract}


physical barriers, psychological disorders and obstacles framework thinking that cause constraints and impacts that affect the smoothness of an event.

Keywords: account executive; event; organizational communication; project team

\section{PENDAHULUAN}

Di Indonesia, bisnis jasa pelaksanaan suatu acara, event organizer (EO) atau tepatnya event manager, merupakan jenis pekerjaan yang tergolong baru. Tumbuhnya bisnis EO beriringan dengan semakin maraknya dunia showbiz dan bangkitnya perekonomian Indonesia setelah krisis moneter tahun 1997 (Natoradjo, 2011).

Saat ini, EO banyak bergerak di bidang pertunjukan musik, pameran produk (mobil, komputer, handycraft), peluncuran produk, dan wedding party. Sesungguhnya praktek EO di Indonesia sudah ada sejak tahun 1990an, dimulai dari pesta-pesta adat yang panitia pestanya membagi berbagai tugas untuk mendukung suksesnya suatu acara. Pembagian tugas ini juga ada pada acara kematian dan pesta adat lainnya (Syaikhon, 2013).

Sejak berkembangnya penyelenggaraan eksibisi atau expo perusahaan dalam memperkenalkan produknya, mulai banyak perusahaan memiliki divisi khusus untuk menangani kegiatan event perusahaan. Namun, sejak krisis ekonomi tahun 1990 sampai awal tahun 2000, divisi ini hanya menjalankan fungsinya pada saat tertentu saja, sehingga perusahaan menutup divisi tersebut. Sebagai gantinya, perusahaan dengan EO dari luar perusahaan untuk menjalankan event perusahaan tersebut (Noor, 2017).

Peluang bisnis EO cukup cerah karena kegiatan orang-orang zaman sekarang ingin serba instan dan tidak mau repot dengan urusan-urusan yang rumit. Beberapa event besar masih menggunakan EO dari luar daerah, tentu saja ini merupakan peluang bagi pebisnis EO di berbagai daerah (Syaikhon, 2013).

Pada dasarnya EO bertugas membantu klien agar dapat menyelenggarakan acara yang diinginkan. Tugas EO mengorganisir segala keperluan event mulai dari tahap persiapan (pra produksi), event berjalan dengan baik dan lancar (produksi) serta pelaporan dan evaluasi pasca kegiatan (Hafidz, 2017). Agar event berjalan dengan baik dan sukses, maka penyelenggaraan event harus melalui sebuah proses yang terdiri dari beberapa tahap. Goldblatt dan Silvers (dalam Natoradjo, 2011) mengungkapkan, proses itu terdiri dari lima tahap: melakukan penelitian, membuat desain event, merencanakan (planning), mengkoordinasikan pelaksanaan event, dan melakukan penilaian atau evaluasi. 
Struktur organisasi sebuah EO disesuaikan dengan acara yang akan diselenggarakan. Struktur itu biasanya terdiri dari lima divisi utama: operasional pelayanan pengunjung, operasional pelayanan pendukung, marketing, administrasi, dan keuangan (Noor, 2017).

Lima divisi utama itu juga ada dalam struktur organisasi PT. Talenta Wirama Berkat ("Twisbless"), sebuah perusahaan jasa event organizer di Jakarta, yaitu: tim project, tim produksi, account executive, tim kreatif, tim finance dan support. Tugas Project Team adalah mengatur flow acara, mengatur teknis event, mengkoordinir semua pihak yang terlibat dalam event, mematangkan konsep bersama creative team dan account executive. Selain itu menjalankan konsep yang sudah disetujui klien. Oleh karena itu, Project Team harus memiliki pola komunikasi yang baik sehingga saat agar event dapat berjalan dengan lancar dan meminimalkan resiko terjadinya kesalahan teknis saat event berlangsung.

Sedangkan Account Executive bertugas untuk bertemu dan berhubungan dengan klien untuk membahas event seperti apa yang diinginkan, menyampaikan beberapa pilihan konsep dan ide dari creative team dan project team, dan dealing dengan klien. Posisi Account Executive adalah jembatan antara klien dengan Project Team dan Creative Team.

Setelah semua materi konsep dari klien didapatkan, Account Executive menyampaikan konsep tersebut kepada Project Team (Project Manager \& Project Officer) untuk membahas kelayakan konsep tersebut dan melakukan pembahasan revisi konsep apabila konsep dari klien dianggap kurang bagus atau kurang layak. Pembahasan konsep ini dilakukan melalui meeting internal yang melibatkan creative team dan production team untuk membahas desain materi promosi, desain produksi seperti booth, ornamen event.

Meningkatnya persaingan industri bisnis manajemen acara membuat setiap event organizer bersaing dalam merancang dan menghasilkan sebuah acara yang menarik, kreatif, dan bernilai tinggi. Sangat penting bagi sebuah event organizer untuk memiliki manajemen komunikasi organisasi yang baik dan efektif untuk menghasilkan acara bernilai tinggi serta dapat membuat klien puas dengan pelayanan event organizer tersebut.

Sebagai salah satu event organizer di Jakarta, Twisbless sudah beroperasi sejak September 2009 dalam bidang pemasaran dan manajemen acara seperti Brand Activation, Peluncuran Produk, Pameran, Seminar, Konferensi, dan Company Gathering. Twisbless berupaya untuk terus mengembangkan pola komunikasi organisasi di perusahaan tersebut agar bisa bertahan dan berkembang menjadi event organizer terbaik. Namun, sering terjadi miss-communication antara Project Team dan Account Executive, menyebabkan jadwal produksi tidak sesuai dengan timeline. Oleh karena itu, penelitian ini ingin meneliti pola komunikasi organisasi antara Project Team dan Account Executive dengan rumusan masalah: "Bagaimanakah arus komunikasi organisasi yang diterapkan oleh event organizer Twisbless?" 
Menurut Liliweri (2014), komunikasi organisasi adalah studi tentang bagaimana orang-orang yang bekerja di dalam organisasi berkomunikasi dalam konteks organisasi, serta interaksi dan pengaruh antara struktur organisasi dalam perorganisasian. Pace dan Faules menambahkan, komunikasi organisasi merupakan pertunjukkan dan penafsiran pesan di antara unit komunikasi yang merupakan bagian dari suatu organisasi tertentu. Suatu organisasi terdiri dari unit-unit komunikasi dalam hubungan hierarkis antara yang satu dengan yang lainnya dan berfungsi dalam lingkungan (Pace dan Faules, 2013).

Berdasarkan ruang lingkupnya, Lawrence D. Brennan (dalam Effendy, 2011) mengatakan komunikasi organisasi terdiri atas dua komunikasi internal dan eksternal. Komunikasi internal adalah pertukaran gagasan di antara para administrator dan karyawan dalam suatu institusi yang menyebabkan terwujudnya institusi dengan strukturnya yang khas (organisasi). Selain itu terwujudnya pertukaran gagasan secara horizontal dan vertikal di dalam perusahaan atau jawatan yang menyebabkan pekerjaan berlangsung (operasi dan manajemen). Sedangkan komunikasi eksternal ialah komunikasi antara pimpinan organisasi dengan khalayak di luar organisasi. Komunikasi eksternal terdiri atas dua jalur secara timbal balik, yakni komunikasi dari organisasi kepada khalayak dan dari khalayak kepada organisasi.

Arus atau aliran informasi dalam suatu organisasi adalah suatu proses dinamis. Dalam proses inilah pesan-pesan secara tetap dan berkesinambungan diciptakan, ditampilkan, dan diinterpretasikan. Proses ini berlangsung terus dan berubah secara konstan. Artinya, komunikasi organisasi bukanlah sesuatu yang terjadi kemudian berhenti. Komunikasi terjadi sepanjang waktu.

Arus komunikasi organisasi terbagi empat (Gambar 1), yaitu: (1) Komunikasi ke Bawah (Downward Communication). Informasi mengalir dari jabatan berotoritas lebih tinggi kepada mereka yang berotoritas lebih rendah; (2) Komunikasi ke Atas (Upward Communication). Informasi mengalir dari tingkat yang lebih rendah (bawahan) ke tingkat yang lebih tinggi; (3) Komunikasi Horizontal. Terdiri dari penyampaian informasi di antara rekan-rekan sejawat dalam unit kerja yang sama. Unit kerja meliputi individu-individu yang ditempatkan pada tingkat otoritas yang sama dalam organisasi dan mempunyai atasan yang sama; (4) Komunikasi Lintas Saluran. Penyampaian informasi melewati batas-batas fungsional dengan individu yang tidak menduduki posisi atasan maupun bawahan mereka (Pace \& Faules, 2013).

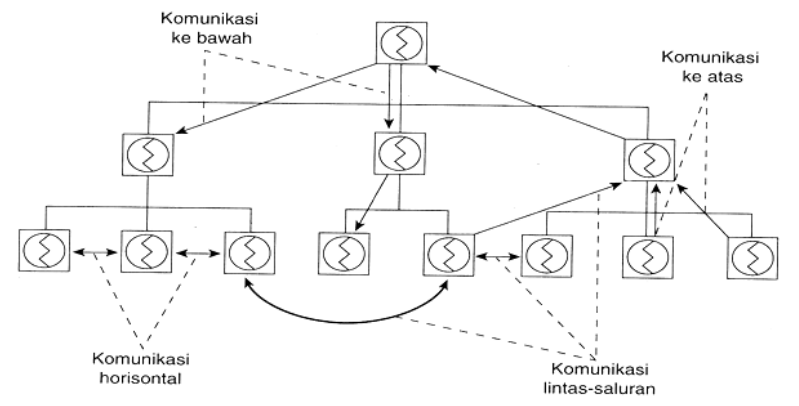

Gambar 1. Empat Arah Komunikasi Organisasi 
Dalam sebuah organisasi, komunikasi yang dilakukan tidak selalu berjalan mulus. Terkadang ada hal yang membuat komunikasi antara suatu organisasi terganggu dan terhambat sehingga menghasilkan suatu informasi yang salah atau menghasilkan misunderstanding diantara orang-orang di dalam organisasi tersebut.

Menurut Cangara (2016), ada beberapa faktor yang menyebabkan komunikasi organisasi terhambat, yakni: (1) Gangguan teknis. Terjadi jika kesalahan suatu alat yang digunakan dalam berkomunikasi mengalami gangguan, sehingga informasi yang ditransformasikan sulit untuk diterima atau dipahami oleh komunikan; (2) Gangguan semantik. Terjadi disebabkan kesalahan pada bahasa yang digunakan; (3) Gangguan psikologi, terjadi karena adanya gangguan yang disebabkan oleh persoalan-persoalan dalam diri individu; (4) Rintangan fisik atau organik, disebabkan karena kondisi geografis misalnya jarak sosial di antara peserta komunikan, seperti senior dan junior; (5) Rintangan kerangka berfikir, disebabkan adanya perbedaan persepsi antara komunikator dan komunikan terhadap khalayak yang digunakan dalam berkomunikasi, ini disebabkan latar belakang pengalaman dan pendidikan yang berbeda; (6) Rintangan budaya, disebabkan adanya perbedaan norma, kebiasaan dan nilai yang dianut oleh pihak-pihak yang terlibat dalam komunikasi.

\section{METODE PENELITIAN}

Penelitian ini adalah kualitatif dengan informan karyawan Twisbless yang menjabat sebagai Head of Project Division, Project Manager, Project Officer dan Account Executive. Penelitian dilakukan pada Desember 2017 sampai April 2018. Teknik pengambilan data yang digunakan adalah observasi dan wawancara. Dalam penelitian ini, teknik analisis hasil wawancara menggunakan teknik analisis dan struktus analisis strategi umum, struktur analisis linear dan struktur komparatif. Penelitian ini menggunakan dua macam cara triangulasi data, yaitu triangulasi sumber dan triangulasi metode untuk mengecek ulang derajat kepercayaan dengan wawancarai seorang event organizer expert dan empat orang karyawan Twisbless. Ada pun fokus penelitian (Tabel 1 ) adalah sebagai berikut :

Tabel 1. Fokus Penelitian

\begin{tabular}{lcc}
\hline \multicolumn{2}{c}{ Objek Penelitian: Komunikasi Organisasi Internal antara Project Team dan Account Executive } \\
\hline Elemen & Dimensi & Evidensi \\
\hline Komunikasi & 1. Arus & 1. Instruksi dan pengarahan dari Head of Project Division ke \\
Vertikal & Komunikasi & Project Team \\
& ke Bawah & 2.Evaluasi hasil event dari Event Project Manager ke Project Team \\
& & 3. Informasi mengenai perubahan instruksi dari Head of Project \\
& Division ke Project Team \\
\hline & 2.Arus & 1.Evaluasi hasil kerja event dari Project Team ke Event Project \\
& Komunikasi & Manager \\
& ke Atas & \\
\hline
\end{tabular}




\begin{tabular}{ll}
\hline & 2.Keluhan dan masukan ide dari Project Team ke Event Project \\
& Manager \\
\hline Komunikasi & 1.Diskusi mengenai kematangan konsep antara Project Manager \\
dan Account Executive & 2.Pemecahan masalah dan hambatan event dengan sesama \\
& Project Officer Team \\
3.Koordinasi tugas antara Project Manager dan Account Executive \\
\hline 1.Diskusi mengenai konsep antara Project Team dan Account \\
Executive \\
2.Pelaksanaan koordinasi tugas antara Project Team dan Account \\
Executive \\
\hline Hambatan & Hambatan yang terjadi pada segala arus komunikasi antara Project \\
& Team dan Account Executive. \\
\hline
\end{tabular}

\section{HASIL DAN PEMBAHASAN}

Proses komunikasi yang dilakukan oleh tim event organizer dengan klien sejak awal pitching hingga terselenggaranya event tersebut dapat dilihat pada Gambar 2:

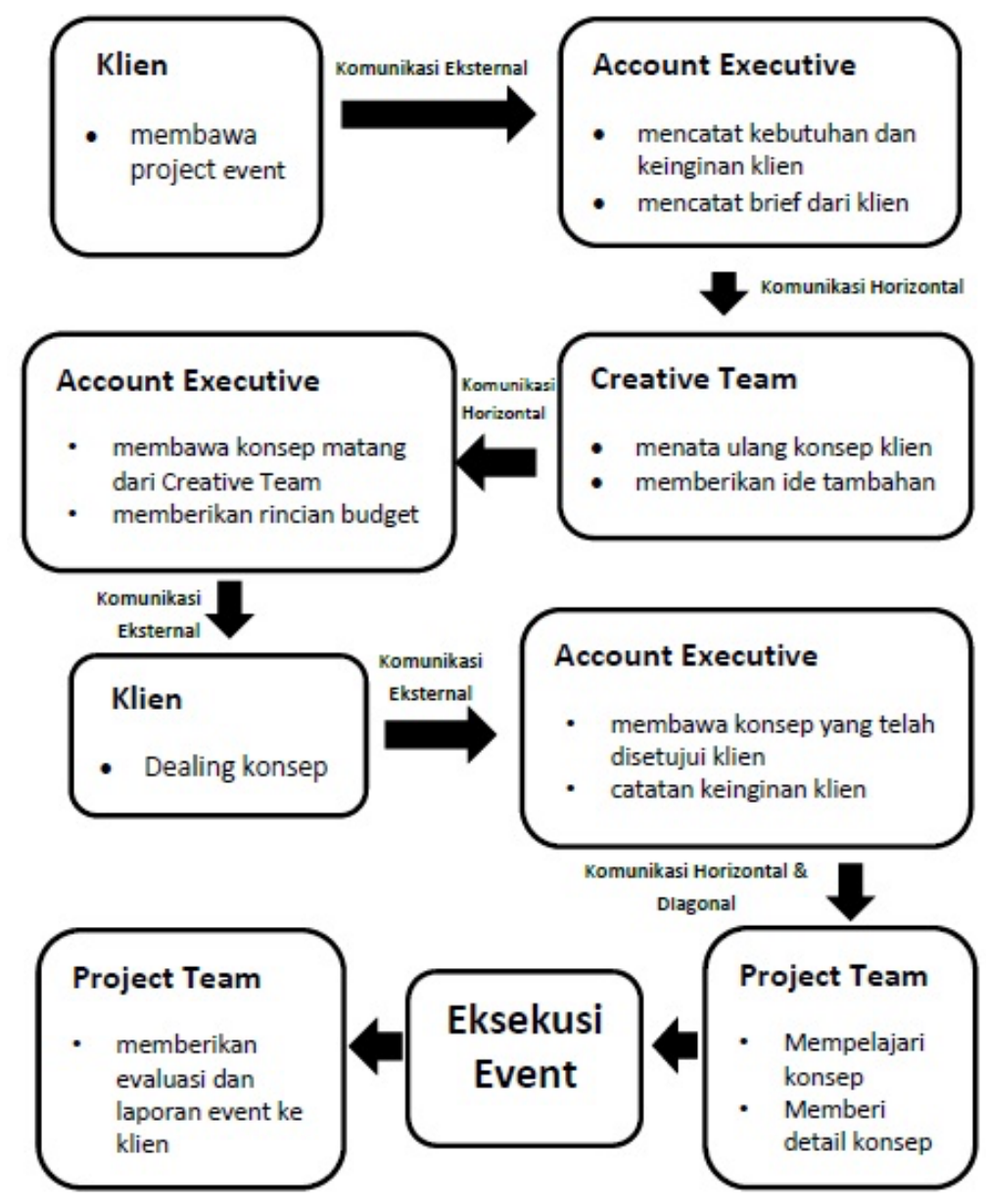

Gambar 2. Proses Komunikasi Saat Pengadaan Event 
Pertemuan klien dengan EO. Langkah awal proses mengadakan event dimulai dari klien yang akan mengundang tim event organizer yang meliputi account executive dan tim kreatif untuk di briefing mengenai kebutuhan event dan gambaran konsep yang diinginkan. Kepada account executive, klien memberikan rincian budget yang akan mereka keluarkan untuk event yang akan dijalankan. Komunikasi yang dilakukan oleh klien dengan account executive merupakan komunikasi eksternal.

Briefing Konsep. Setelah itu, account executive mengadakan briefing internal dengan tim kreatif mengenai konsep yang nantinya akan dikembangkan semenarik mungkin oleh tim kreatif dengan tujuan agar perusahaan menang pitching project event tersebut. Komunikasi yang dilakukan antara account executive dengan tim kreatif merupakan komunikasi horizontal. Setelah konsep tersebut matang oleh tim kreatif, account executive akan mengecek terlebih dahulu apakah konsep tersebut dapat diimplementasikan dengan batasan budget yang klien inginkan.

Pengajuan Proposal ke Klien. Jika konsep sudah cocok dengan budget yang dihitung account executive, account executive kemudian akan memberikan konsep tersebut yang sudah disusun menjadi proposal ke klien.

Persetujuan dan Perjanjian Proposal. Jika konsep yang dibuat oleh tim kreatif telah disetujui klien, account executive akan melakukan dealing dengan klien dan membuat perjanjian mengenai pembagian tugas untuk menjalankan event tersebut

Persiapan Materi. Setelah klien menyetujui konsep, account executive langsung memberikan brief kepada tim project mengenai konsep tersebut di mana dalam tim project terdapat head of project division, project manager dan project officer. Konsep tersebut kemudian akan dijabarkan lagi secara detail oleh tim project untuk disusun menjadi manual book serta checklist yang akan menjadi acuan project officer dalam mengeksekusi event sesuai dengan flow yang telah disusun. Komunikasi horizontal yang terjadi pada proses ini adalah komunikasi yang dilakukan antara account executive dan project manager, sedangkan komunikasi diagonal terjadi pada komunikasi yang dilakukan antara account executive dengan head of project division dan project officer.

Eksekusi. Dalam proses ini, yang betugas di lapangan hanyalah tim project. Di lapangan, tim project akan mengurus dan melengkapi semua kebutuhan event sesuai dengan checklist dan timeline yang telah dibuat sebelumnya. Dalam proses ini, komunikasi vertikal terjadi pada saat head of project division memberikan arahan di lapangan kepada project manager maupun project officer.

Evaluasi. Setelah event selesai, tim project akan membuat evaluasi serta report tentang event yang telah diselenggarakan yang nanti akan dibawakan ke klien saat meeting evaluasi. Proses 
komunikasi yang terjadi saat tim project memberikan evaluasi dan report event merupakan komunikasi eksternal.

Hasil penelitian ini memperkuat pernyataan Suseno (2005) bahwa proses yang harus dilalui dalam mengadakan event antara lain adalah pertemuan antara klien dan EO, pengajuan proposal kepada klien, persetujuan dan perjanjian proposal dan persiapan materi.

Arus komunikasi internal dan eksternal Twisbless meliputi:

(1) Arus Vertikal (Atas). Project Manager ke Head of Project Division. Membahas plotting tim yaitu pembagian tim untuk event-event yang akan dijalankan dan membahas kerjasama dengan EO partner untuk event yang diselenggarakan di luar kota Jakarta. Komunikasi arus atas yang dilakukan terjadi hampir setiap hari melalui telepon.

Sementara itu, Project Officer ke Head of Project Division dan Project Manager. Membahas idealisme pekerjaan. Komunikasi arus atas yang dilakukan sering terjadi saat adanya event. Komunikasi dilakukan secara langsung melalui forum ataupun meeting dan secara tidak langsung melalui media komunikasi seperti whatsapp group, email, ataupun telepon.

(2) Vertikal (Bawah). Head of Project Division ke Project Manager dan Project Officer. Membahas kebutuhan man power yaitu kru tambahan (freelancer) untuk membantu melancarkan event yang sedang berjalan, lalu membahas key performance indicator (KPI) project event, koodirnasi budget account executive sebagai cross-check agar margin perusahaan tetap stabil, dan koordinasi dengan vendor untuk event besar yang membutuhkan banyak equipment. Komunikasi arus ke bawah dilakukan secara langsung melalui meeting internal minimal seminggu sekali. Jika event yang berlangsung banyak, komunikasi dapat terjadi dua kali dalam seminggu, sedangkan komunikasi yang dilakukan melalui media komunikasi seperti whatsapp group terjadi setiap hari.

Project Manager ke Project Officer. Membahas masalah flow event dan update mengenai event yang sedang berjalan. Komunikasi arus bawah yang dilakukan secara langsung atau tatap muka jarang terjadi, hanya saat weekly meeting seminggu sekali, tetapi komunikasi yang dilakukan melalui media komunikasi dengan bawahannya sering terjadi melalui telepon.

(3) Horizontal. Project Manager ke Account Executive. Membahas perubahan tim koordinasi dari klien. Komunikasi arus horizontal sering terjadi hampir setiap hari melalui tatap langsung pada saat meeting maupun melalui media komunikasi yaitu telepon.

Account Executive ke Project Manager. Membahas masalah pemahaman project yang sedang ingin dijalankan. Komunikasi arus horizontal sering terjadi, sebanyak tiga kali dalam seminggu melalui tatap langsung saat meeting di kantor maupun saat meeting di luar kantor, sedangkan komunikasi melalui media komunikasi seperti whatsapp dan email terjadi setiap hari. 
(4) Diagonal. Head of Project Division ke Account Executive. Membahas budget, deadline yang diberikan oleh klien, manual book untuk project officer dan kru yang menjalankan event dan checklist kebutuhan event. Komunikasi arus diagonal dengan Account Executive sering kali terjadi bahkan setiap saat melalui tatap langsung di kantor maupun melalui whatsapp group.

Project Officer ke Account Executive. Membahas project approval, yaitu pengajuan ide maupun saran ke klien mengenai event yang mempengaruhi budget yang akan dikeluarkan oleh klien. Selain itu, juga membahas margin keuntungan perusahaan. Komunikasi arus diagonal yang dilakukan biasanya terjadi satu sampai dua kali seminggu melalui meeting. Tetapi, saat mendekati hari $\mathrm{H}$ event, komunikasi dilakukan setiap hari di hari kerja melalui media komunikasi seperti whatsapp group, email dan telepon.

Account Executive ke Head of Project Division dan Project Officer. Membahas checklist event yaitu kebutuhan event, timeline event (rundown), dan briefing mengenai project event yaitu membicarakan bagaimana nanti tim project akan mengimplementasikan konsep yang sudah dibuat oleh tim kreatif serta memberikan info tentang apa yang klien ingin wujudkan dan ekspektasikan dari event tersebut agar saat tim project merealisasikan konsep tersebut klien puas dan sesuai dengan kemauannya. Komunikasi arus diagonal yang dilakukan sangat sering terjadi, yaitu tiga kali dalam seminggu melalui tatap langsung saat meeting dan setiap hari melalui media komunikasi seperti whatsapp group dan email.

(5) Eksternal. Head of Project Division ke klien. Membahas persiapan event yaitu apa saja yang klien butuhkan, target event yang sedang dijalankan dan evaluasi mengenai event yang telah dijalani.

Project Manager ke klien. Membahas tentang masalah hasil survey lokasi event. Project Officer ke klien. Membahas masalah mengenai printing dan design approval yaitu desain untuk banner, backdrop, souvenir event, poster ataupun desain cetak yang akan digunakan untuk mendukung event klien, gimmick yang biasanya berbentuk souvenir maupun material pendukung event dan talent untuk pengisi acara.

Account Executive ke klien. Membahas mengenai tim internal dari sisi klien dan approval budget yaitu permintaan maupun penawaran yang diajukan saat pihak EO memberikan saran untuk event yang berdampak pada budget yang dikeluarkan oleh klien.

Hambatan komunikasi organisasi yang terjadi di lingkungan Twisbless meliputi:

Arus Vertikal yaitu rintangan fisik atau organik berupa jauhnya jarak antara satu sama lain, seperti aat rekan kerja sedang diluar kota untuk menjalankan event lain; dan gangguan psikologi, yaitu ego dari masing-masing individu terkadang masih sulit untuk ditahan. 
Arus Vertikal (Bawah). Faktor rintangan kerangka berpikir berupa perbedaan pendapat atau persepsi, seperti perbedaan pendapat dan pengetahuan terkait kebutuhan event. Gangguan teknisnya berupa sulitnya rekan kerja untuk dihubungi karena sedang menjalankan pekerjaan yang lain.

Arus Horizontal, berupa gangguan psikologi berupa kurangnya fokus dalam pekerjaan dan saling lupa untuk memberi kabar mengenai update dari klien. Gangguan teknisnya, kurangnya komunikasi, seperti kurang komunikasi untuk membicarakan dealing project event.

Arus Diagonal. Gangguan teknis berupa kurangnya waktu untuk bertemu dan melakukan komunikasi, seperti sulit bertemu untuk berdiskusi karena waktu yang minim, keadaan sedang hectic dan adanya pekerjaan yang lain saat weekend.

Arus Eksternal. Gangguan semantik berupa kesalahpahaman yang disebabkan oleh kata-kata atau bahasa yang digunakan dalam media komunikasi. Contohnya: komunikasi yang dilakukan lewat whatsapp atau email tidak memberikan hasil yang baik karena adanya kesalahpahaman atas bahasa yang digunakan serta perbedaan persepsi yang timbul karena pengertian yang salah saat berkomunikasi di whatsapp. Gangguan psikologinya berupa lupa. Contoh: lupa dengan hal yang klien minta sehingga kehendak klien tidak terpenuhi.

\section{Pendapat Informan Ahli Event Organizer}

Berdasarkan analisis di atas, komunikasi yang dilakukan antara tim project dengan account executive menurut informan ahli, sangat penting untuk melancarkan event. Jika komunikasi tidak berjalan dengan baik, maka tim internal EO tidak akan mengetahui dengan tuntas apa yang diinginkan dan diharapkan klien pada eventnya. Komunikasi yang dilakukan tim internal EO dengan klien, informan ahli menanggap penting untuk memuaskan klien dengan pelayanan jasa yang diberikan EO. Tanpa adanya komunikasi yang baik, tim EO tidak akan bisa mengtahui perubahan-perubahan yang mungkin terjadi saat event berlangsung. Berbicara soal perubahan, hal tersebut harus diketahui oleh klien dan klien berhak mendapatkan informasi tentang perubahan dan kendala yang terjadi saat event berlangsung. Maka dari itu, komunikasi dinilai sangat penting sekali untuk dijaga.

Menurut informan ahli, proses arus komunikasi yang dilakukan tim project dan account executive dalam menangani event dari klien sudah benar, karena pada dasarnya proses arus komunikasi yang dilakukan tim EO untuk menangani klien adalah seperti yang dilakukan project team dan account executive di Twisbless. Informan menambahkan, manfaat dari kelancaran arus komunikasi tersebut adalah event akan menjadi sukses. Dia menilai proses komunikasi tim project maupun account executive di Twisbless dalam menangani kliennya sudah efektif, karena telah mengikuti flow event yang benar sehingga pekerjaan tim project di lapangan telah sesuai dengan flow yang ada. 
Disamping itu, informan ahli juga memberikan beberapa saran untuk tim project dan account executive agar hambatan komunikasi yang sering mereka temui dapat diminimalisir, yaitu saran untuk lebih sering mengadakan briefing jika ada kendala sering ditemukan berupa sulitnya bertemu satu sama lain dan menggunakan media komunikasi sebaik mungkin agar komunikasi tidak terputus sehingga permasalahan di lapangan dapat dikomunikasikan sesegera mungkin.

\section{SIMPULAN}

Bentuk komunikasi organisasi yang dilakukan oleh project team dan account executive di event organizer Twisbless dibagi menjadi dua dimensi yaitu internal dan eksternal. Dimensi internal dibagi lagi menjadi empat arus komunikasi yaitu komunikasi arus atas, komunikasi arus bawah, komunikasi horizontal, dan komunikasi diagonal. Hambatan komunikasi dalam proses komunikasi project team dan account executive di event organizer Twisbless masih banyak terjadi. Hambatan tersebut adalah gangguan teknis berupa minimnya waktu berkomunikasi yang disebabkan kuantitas pekerjaan; gangguan semantik berupa kesalahpahaman atas diksi yang digunakan dalam bertelepon, email dan whatsapp group; gangguan psikologi berupa kurangnya fokus pada pekerjaan dan lupa pada tugas yang diberikan klien; rintangan fisik berupa jauhnya jarak geografis antara satu sama lain; dan rintangan kerangka berpikir berupa perbedaan pendapat dan persepsi.

Hambatan yang terjadi dapat memberikan dampak dan kendala yang mempengaruhi kinerja: hasil yang berikan tidak sesuai dengan tujuan dan ekspektasi. Walau ada hambatan komunikasi, namun Event Project Team dan Account Executive di Twisbless bisa mengatasi persoalan dengan mengadakan meeting saat komunikasi mulai terhambat dan berusaha menyelesaikan permasalahan-permasalahan yang ada untuk dirundingkan bersama melalui meeting, serta menggunakan media komunikasi yang ada seperti telepon untuk berkomunikasi jika jarak mereka saling berjauhan.

\section{DAFTAR PUSTAKA}

Cangara, H. (2016). Pengantar Ilmu Komunikasi. Jakarta: PT RajaGrafindo Persada.

Effendy, O. U. (2011). Ilmu Komunikasi: Teori dan Praktek. Bandung: PT Remaja Rosdakarya. Liliweri, A. (2014). Sosiologi \& Komunikasi Organisasi. Jakarta: PT Bumi Aksara.

Mulyana, D. (2013). Ilmu Komunikasi: Suatu Pengantar. Bandung: PT Remaja Rosdakarya. Natoradjo, S. (2011). Dasar-Dasar Event Management. Jakarta: Gramedia Pustaka Utama. Noor, A. (2017). Manajemen Event. Bandung: Alfabeta.

Pace, R. W., \& Faules, D. F. (2013). Komunikasi Organisasi. Bandung: PT Remaja Rosdakarya. Suseno, I. K. (2005). Cara Pinter Jadi Event Organizer. Yogyakarta: Galang Press. 
Syaikhon, A. (2013). Sejarah Event Organizer di Indonesia. Diperoleh 08 November 2017 dari: http://www.neraca.co.id/article/36565/sejarah-event-organizer-di-indonesia

Twisbless. (n.d.). Homepage. Diperoleh 08 November 2017 dari http://www.twisbless.com/ 